\title{
Association of Antidiabetic Treatment with the Type of Obesity in Type 2 Diabetic Patients
}

\section{Jawariea Ali, ${ }^{1}$ Sheikh Sajjad Ali, ${ }^{2}$ Muhammad Imran, ${ }^{3}$ Tuba Tariq, ${ }^{4}$ Umair Mahmood, ${ }^{5}$ Junaid Iqbal $^{6}$}

\begin{abstract}
Objective: To find association between antidiabetic treatment and the type of obesity in type 2 diabetic patients.

Methods: The study was conducted in National Institute of Diabetes \& Endocrinology (NIDE), Karachi, over a period of 6 months, ie. from January to June, 2018. It was an observational analytical study, for which 59 patients were selected via non-probability sampling, as per inclusion and exclusion criteria. Data was collected through detailed history, examination. A database was developed and analyzed on SPSS 17. A pvalue $<0.05$ was taken as statistically significant.

Results: Fifty nine patients fulfilling the inclusion criteria were included in this study. While $30(50.8 \%)$ had generalized obesity, $29(49.2 \%)$ were not having generalized obesity. Further it was observed that $35(59.3 \%)$ had abdominal obesity, while $24(40.7 \%)$ were not having abdominal obesity. A total of $39(66.1 \%)$ were on insulin, while $20(43.9 \%)$ were not on insulin. Finally, $41(69.5 \%)$ were on oral hypoglycemic drugs, while 18 $(30.5 \%)$ were not on oral hypoglycemic drugs. P-values were not significant for the study parameters.

Conclusion: There is no association between antidiabetic treatment and type of obesity in type 2 diabetic patients.

Key Words: Diabetes, obesity, body mass index, insulin, oral hypoglycemic drugs

How to Cite: Ali J, Ali S.S, Imran S, Tariq T, Mahmood U, Iqbal J. Association of antidiabetic treatment with the type of obesity in type 2 diabetic patients. Esculapio.2020;16(04):97-100.
\end{abstract}

DOI: https://doi.org/10.51273/esc20.2516421

\section{Introduction}

$\mathrm{O}$ besity is intercontinental issue. ${ }^{1}$ In USA alone, more then $2 / 3 \mathrm{rd}$ of population is morbidly obese. ${ }^{2}$ A study conducted in 2006 suggested that a quarter of the Pakistani population falls in the overweight or obese category. ${ }^{3}$ This was calculated by quantifying them according to Indo-Asian specific BMI cut off values. According to the 2016 World Health Organization (WHO) statistics, $20.8 \%$ of the

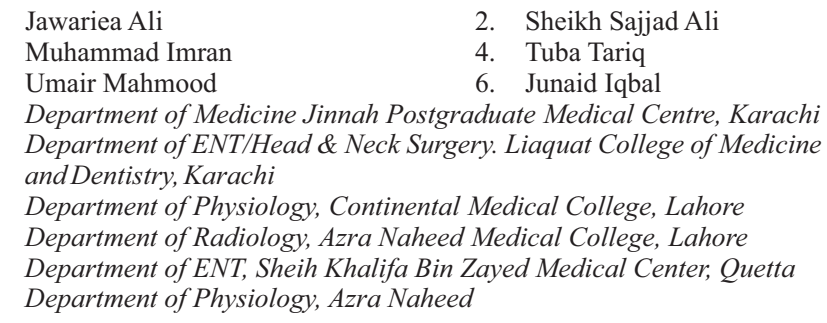

Correspondence:

Dr. Muhammad Imran, Associate Professor, Department of Physiology, Continental Medical College, Lahore

Submission Date:

1st Revision Date:

Acceptance Date:

22-12-2020

$04-12-2020$

22-12-2020 population is overweight and $4.8 \%$ is obese. ${ }^{4}$ Studies done in Pakistan have labeled obesity as an epidemic. ${ }^{5}$ The relationship between human fat and metabolic disorders are not completely understood, although excess body fat is linked with cardiovascular disease risk. ${ }^{6}$ Obesity is directly related to BMI and adiposity is amount of human fat accumulated and it represents excess load of human body fat. ${ }^{7}$ Body mass index is a measure for human body shape based on an individual's mass and height. ${ }^{8}$ According to the World Health Organization, normal BMI is $\leq 25.0 \mathrm{~kg} / \mathrm{m}^{2}$ and generalized obesity is defined as BMI of or more than 30. And according to a WHO expert consultation on appropriate BMI for Asian population, the range for acceptable normal or optimum BMI should be narrowed to $18.5-23 \mathrm{~kg} / \mathrm{m}^{2}$, but the criteria for obesity is still BMI 30 or more. ' Abdominal obesity is defined as WC of $90 \mathrm{~cm}$ or more for men and $80 \mathrm{~cm}$ or more for women according to the International Diabetes Federation for Asian populations. Abdominal obesity, also known as belly fat or clinically as central obesity, 
is considerable abdominal fat around the stomach and abdomen. $^{10}$

\section{Methods}

The study was conducted in National Institute of Diabetes \& Endocrinology (NIDE), Karachi, over a period of 6 months, i.e. from January to June, 2018. It was an observational analytical study. A sample size of 59 was calculated using standard formula: $n=z^{2}$. P $(1-\mathrm{P}) / \mathrm{m}^{2}$, where $\mathrm{n}$ is the sample size, $\mathrm{z}$ is the confidence level at $95 \%$ (standard value of 1.96), $\mathrm{P}$ is the prevalence of disease, and $\mathrm{m}$ is the margin of error at $5 \%$ (standard value of 0.05 ). The sample size was verified by the help of computer software PASS (Power Analysis and Sample Size) version 2015, at $90 \%$ power of the test and an alpha of 0.05 . Patients, coming to OPD of NIDE, were selected via nonprobability (convenient) sampling.

Data was collected through detailed history and examination (general physical, systemic examination, biometrics). Data source included the records of diabetic patients treated in NIDE, Karachi and the data was used to categorize the patients according to type of obesity and the type of anti diabetic treatment. A database was developed and analyzed on SPSS 17. Mean and SD was calculated for age. Frequency and percentages were calculated for gender, waist circumference, BMI, use of insulin and use of oral hypoglycemic drugs and outcome variable ie. generalized and abdominal obesity. Effect modifier was controlled through stratification of age, gender, insulin use and oral hypoglycemic drugs. It was done to see their effect, on outcome variables, applying chi square test. Ap-value of $<0.05$ was taken statistically significant.

\section{Results}

In this study, 59 diabetic patients, both males and females, fulfilling the inclusion criteria, were included. On analysis of demographics data it was observed that $42(71.2 \%)$ were males while $17(28.8 \%)$ were females. A total of $36(61 \%)$ patients were below 60 years of age while 23(39\%) were 60 years or above of age. While $30(50.8 \%)$ had generalized obesity, 29(49.2\%) were not having generalized obesity. Further it was observed that $35(59.3 \%)$ had abdominal obesity, while $24(40.7 \%)$ were not having abdominal obesity. A total of 39(66.1\%) were on insulin, while $20(43.9 \%)$ were not on insulin. Finally, $41(69.5 \%)$ were on oral hypoglycemic drugs, while $18(30.5 \%)$ were not on oral hypoglycemic drugs.
Stratification and analysis of observed data is given in Tables 1-4:

Table 1: Analysis of Insulin use with Generalized Obesity

\begin{tabular}{cccc} 
Insulin use & \multicolumn{2}{c}{ Generalized obesity } & P - \\
\cline { 2 - 3 } value \\
Yes (39) & No (29) & 0.09 \\
No (20) & 13 & 26 & \\
& 17 & 03 & \\
\hline
\end{tabular}

Table 2: Analysis of Oral Hypoglycemic Drugs use with Generalized Obesity

\begin{tabular}{|c|c|c|c|}
\hline \multirow{2}{*}{$\begin{array}{c}\text { Oral hypoglycemic } \\
\text { drugs }\end{array}$} & \multicolumn{2}{|c|}{ Generalized obesity } & \multirow{2}{*}{$\begin{array}{c}P \text { - } \\
\text { value }\end{array}$} \\
\hline & Yes (30) & No (29) & \\
\hline Yes (41) & 16 & 25 & 0.06 \\
\hline No (18) & 14 & 04 & \\
\hline
\end{tabular}

Table 3: Analysis of Insulin use with Abdominal Obesity

\begin{tabular}{cccc} 
Insulin use & \multicolumn{2}{c}{ Abdominal obesity } & P - \\
\cline { 2 - 2 } Yes (39) & Yes (35) & No (24) & value \\
No (20) & 24 & 15 & 0.17 \\
\hline
\end{tabular}

\section{Discussion}

Our study compared the type of antidiabetic treatment on the type of obesity, using 59 diabetic patients. We observed that generalized obesity was more in our patients than abdominal obesity. It was an unfortunate finding that abdominal obesity was invariably present in users of both type of treatments. Hollander in 2007 compared insulin and different oral hypoglycemic drugs in diabetics and concluded an overall weight gain in exclusive insulin users. ${ }^{11}$ One important factor that has been shown to increase abdominal obesity with insulin therapy is hypoglycemia. Frequent hypoglycemia and treatment, often overtreatment, can cause weight gain. ${ }^{12}$ There is also evidence that insulin may play a direct role in fat creation and deposition. ${ }^{13}$ Anderson et al. compared lispro and regular insulin at mealtimes and found no difference in weight gain between the two groups of patients with type 2 diabetes. Reduction in A1C also did not differ between the two groups. ${ }^{14}$ Cheng in 2011 considered different pharmacotherapeutic options in type 2 diabetics and proposed that the treatment of diabetes should not only focus on glycemic control as its sole intention, but it should take into consideration the effect of antidiabetic treatment on weight as well, since obesity aggravates insulin resistance, beta cell failure, and cardiovascular risk. ${ }^{15}$ Rosenstock et al. 
Table 4: Analysis of Oral Hypoglycemic Drugs use with Abdominal Obesity

\begin{tabular}{cccc} 
Oral hypoglycemic & \multicolumn{2}{c}{ Abdominal obesity } & P - \\
\cline { 2 - 3 } drugs & Yes (35) & No (24) & value \\
Yes (41) & 24 & 17 & 0.54 \\
No (18) & 11 & 07 & \\
\hline
\end{tabular}

compared the efficacy of insulin analogs detemir and glargine when added to oral glucose lowering agents in insulin-naive type 2 diabetes subjects with baseline HbAlc of $8.6 \%$ in a 52 -week, open-label treat-totarget trial. Treatment with insulin detemir $(n=291)$ and glargine $(\mathrm{n}=291)$ resulted in a comparable decrease in $\mathrm{HbA1c}$ from 8.6 to 7.2 and $7.1 \%$, respectively. However, there were modest reductions in weight gain seen with detemir versus glargine $(+3.0$ $\mathrm{kg}$ versus $+3.9 \mathrm{~kg}, \mathrm{P}=.01) .{ }^{16}$ Holman et al. conducted an open-label multicenter trial to evaluate the efficacy of basal insulin, prandial insulin, and biphasic insulin in type 2 diabetes patients inadequately controlled (mean $\mathrm{HbA} 1 \sim 8.5 \%$ ) on oral hypoglycemic agents. ${ }^{24}$ Patients randomized to prandial insulin $(n=239)$ had a greater weight gain of $6.4 \pm 0.5 \mathrm{~kg}$ compared with patients on biphasic insulin $(\mathrm{n}=235)$ with weight gain of $5.7 \pm 0.5 \mathrm{~kg}$ and basal insulin $(\mathrm{n}=234)$ of $3.6 \pm 0.5$ kg. ${ }^{17}$ Jacob et al. conducted a multicenter doubleblind, placebo-controlled study in which overweight or obese patients with type 2 diabetes (mean $\mathrm{HbA} 1 \mathrm{c} \sim$ $8.5 \%$; BMI $37 \mathrm{~kg} / \mathrm{m}^{2}$ ) on either metformin, sulfonylurea, and/or insulin were randomized to treatment with orlistat $120 \mathrm{mg}$ three times daily $(\mathrm{n}=1279)$ or placebo (n 1271). Patients treated with orlistat had a statistically significant greater decrease in body weight $(-3.8 \mathrm{~kg})$ than placebo-treated patients $(-1.4$ $\mathrm{kg}$ ) and a larger decrease in HbAlc compared with placebo $(-0.74 \%$ versus $-0.31 \%)$. In addition, patients with minimal weight loss $(<1 \%$ of baseline body weight) were also found to have a significant improvement in glycemic control with orlistat (HbA1c-0.29\%) compared with placebo $( \pm 0.14 \%)$ suggesting that improvement of glycemic control associated with orlistat may be independent of weight loss. ${ }^{18}$ Clearly, the weight gain associated with insulin is a major drawback for treating diabetes, especially patients with type 2 diabetes mellitus.

\section{Conclusion}

There is no association between antidiabetic treatment and type of obesity in type 2 diabetic patients.
Diabetics have more abdominal as well as generalized obesity, which is not related to the drug they are taking for control of diabetes.

\section{Conflict of Interest: None}

\section{References}

1. Bays HE. "Sick fat," metabolic disease, and atherosclerosis. Am J Med. 2009;122:S26-S37.

2. Flegal KM, Carroll MD, Kit BK, Ogden CL. Prevalence of obesity and trends in the distribution of body mass index among US adults, 1999-2010. JAMA. 2012;307:491-497.

3. Jafar TH, Chaturvedi N, Pappas G. Prevalence of overweight and obesity and their association with hypertension and diabetes mellitus in an Indo-Asian population. CMAJ 2006; 175: 1071-7.

4. World Health Organization 2016. [online] [cited 2016 Dec 22]. Available from: URL: http:// www. who.int/diabetes/country-profiles/pak_en.pdf?ua=1.

5. Sana Tanzil TJ. Obesity, An Emerging Epidemic in Pakistan: A Review Evidence. J Ayub Med Coll Abbottabad 2016; 28: 597-600

6. Bays HE. Adiposopathy: Is "sick fat" a cardiovascular disease? J Am CollCardiol. 2011; 57: 24612473.

7. National Heart, Lung, and Blood Institute. The Practical Guide: Identification, evaluation and treatment of overweight and obesity in adults. http://www. nhlbi.nih.gov/guidelines/obesity/pretgd_c.pdf. Published Oct 2000. Accessed July 72012.

8. Benn RT. Some mathematical properties of weightfor-height indices used as measures of adiposity. Br J Prev Soc Med. 1971; 25(1): 42-50.

9. Llido LO, Mirasol R: Comparison of body mass index based nutritional status using WHO criteria versus "Asian" criteria. PhilSPEN Online Journal of Parenteral and Enteral Nutrition. 2012, January issue, 1-8.

10. Alberti KG, Zimmet P, Shaw J. Metabolic syndrome - a new world-wide definition. A consensus statement from the International Diabetes Federation. Diabet Med. 2006;23:469-480.

11. Hollander P: Anti-Diabetes and Anti-Obesity Medications: Effects on Weight in People With Diabetes. Diabetes Spectrum 2007, 20 (3); 159-165

12. Strachan MW, Ewing FM, Frier BM, Harper A, Deary IJ: Food cravings during acute hypoglycaemia in adults with type 1 diabetes. Physiol Behav 80: 675-682, 2004

13. Kersten KS: Mechanisms of nutritional and hor- 
monal regulation of lipogenesis. EMBO Rep 2: 282286, 2001

14. Anderson JH Jr, Brunelle RL, Keohane P, Koivisto VA, Trautmann ME, Vignati L, DiMarchi R: Mealtime treatment with insulin analog improves postprandial hyperglycemia and hypoglycaemia in patients with non-insulin-dependent diabetes mellitus. Arch Intern Med 157:1249-1255, 1997

15. Cheng V, Kashyap SR: Weight Considerations in Pharmacotherapy for Type 2 Diabetes. Journal of Obesity. Volume 2011, 1-9

16. Rosenstock J, Davies M, Home PD, Larsen J, Koenen $\mathrm{C}$, and Schernthaner G: "A randomised, 52-week, treat-to-target trial comparing insulin detemir with insulin glargine when administered as add-on to glucose-lowering drugs in insulinnaive people with type 2 diabetes,” Diabetologia, 2008; 51(3), 408-16
17. Holman RR, Thorne KI, Farmer AJ et al., "Addition of biphasic, prandial, or basal insulin to oral therapy in type 2 diabetes," New England Journal of Medicine, 2007; 357(17), 1716-30

18. Jacob S, Rabbia M, Meier MK, Hauptman J: "Orlistat $120 \mathrm{mg}$ improves glycaemic control in type 2 diabetic patients with or without concurrent weight loss," Diabetes, Obesity and Metabolism, 2009;11(4), 36171

\section{Author's Contribution}

JA: Author; Data collection

ASS: Conceived the article; Proof reading

IM: Data analysis

TT: Data analysis, Results compilation

MU: Write up and formatting

IJ: Statistical analysis 